\title{
Different Waist Circumferences, Different Metabolic Risks in Koreans
}

\author{
Nam Seok Joo, Bom Taeck Kim, Sat Byul Park, Mi Hee Kong, Tae Young Lee, and \\ Kwang Min Kim
}

Objective: We investigated the difference in metabolic parameters by waist circumference (WC) and body mass index (BMI) in a population of Korean men and women.

Method: We collected data on 69,535 Korean men and women and performed a cross-sectional analysis of the data. Study subjects were grouped by BMI and WC. We measured metabolic parameters for each group and compared the differences in the metabolic abnormalities. Subjects were grouped as follows: normal group (NG; normal WC and normal BMI); centrally obese group (COG; high WC and normal BMI); generally obese group (GOG; normal WC and high BMI); and combined obese group (COM; high WC and high BMI).

Results: Subjects in the COM group showed more metabolic parameter abnormalities in comparison to the other groups. In men, triglyceride (TG) and fasting blood glucose (FBG) levels were higher in the COG than in the GOG. Correspondingly, total cholesterol (TC), TG, and FBG levels were higher in the female COG than in the female GOG. In addition, the mean numbers of abnormal metabolic parameters in the COG were higher than in the GOG for both men and women. More men and women developed metabolic syndrome in the COG $(39.1 \%$ in men, $33.0 \%$ in women) than in the GOG $(9.7 \%$ in $\mathrm{men}, 7.8 \%$ in women).

Conclusion: Among Koreans, the COG had more metabolic abnormalities and metabolic syndrome than the GOG. (J Am Board Fam Med 2007;20:258-265.)

Worldwide obesity is a serious public health concern that increases the risk of cardiovascular disease (CVD) and diabetes. In Korea (and other Asian countries), more of the population is becoming obese, and many people may be under increasing threat of developing metabolic syndrome. The third national health and nutrition survey conducted by the Korean Ministry of Health and Welfare in 2001 announced that the overall prevalence of obesity (BMI $\left.\geq 25.0 \mathrm{~kg} / \mathrm{m}^{2}\right)$ in Korean adults was $30.6 \%$ (32.4\% in men, $29.4 \%$ in women). ${ }^{1}$

Obesity is related to metabolic syndrome, and it has been shown that subjects with metabolic syndrome are at a greater risk of developing CVD and

This article was externally peer reviewed.

Submitted 25 April 2006; revised 19 November 2007; accepted 28 November 2006.

From the Department of Family Practice and Community Health, Ajou University School of Medicine, Suwon, Republic of Korea.

Funding: none.

Conflict of interest: none declared.

Corresponding author: Kwang Min Kim, Department of Family Practice and Community Health, Ajou University School of Medicine, San 5, Woncheon dong, Young-tong gu, Suwon, Republic of Korea, 443-721 (E-mail: gaksi@ajou.ac.kr). show higher mortality from both CVD and all causes. $^{2-4}$ Metabolic score has also been associated with severity of coronary artery disease. ${ }^{5}$

Body mass index (BMI) and waist circumference (WC) are the 2 most important measurements in the assessment of obesity. However, it has not been determined which of them is more important in assessing the risk of metabolic syndrome. WC is the surrogate for the amount of visceral fat, which is known to predict metabolic syndrome independent of total body fat in various ethnicities. ${ }^{6}$

This study investigated the differences in metabolic parameters among Koreans, divided into 1 normal and 3 obese groups and categorized by BMI and WC.

\section{Research Methods \\ Subjects}

The subjects in this study were taken from a group of 72,301 native Korean men and women who visited for a general health assessment at the Health Promotion Center in a university hospital in Suwon, Korea, between March 1997 and February 2005. We accepted only the first set of data for any subject who visited more than once in the 8 years. 
We excluded people who had cancer or thyroid disease; however, we did not exclude those subjects with hyperlipidemia (5.7\% of subjects), diabetes (4.6\%), or hypertension (11\%). After exclusions, 69,535 Koreans remained in the study.

According to the World Health Organization's Asian obesity guideline for $2000,{ }^{7}$ overweight was defined as $23.0 \leq \mathrm{BMI} \leq 24.9$ and obesity as BMI $\geq 25 \mathrm{~kg} / \mathrm{m}^{2}$. In the $3 \mathrm{rd}$ National Cholesterol Education Program-Adults Treatment Panel III (NCEP-ATP III) Asian guideline, central obesity was defined as $W C \geq 90 \mathrm{~cm}$ for men and $\geq 80$ for women. (In the United States, central obesity was defined as $W C \geq 102$ for men and $\geq 88$ for women.)

We categorized study subjects into the following 4 groups:

- normal group (NG; normal WC and normal BMI);

- centrally obese group (COG; high WC and normal BMI);

- generally obese group (GOG; normal WC and high BMI);

- and combined obese group (COM; high WC and high BMI).

\section{Anthropometry, Blood Pressure (BP), and Laboratory Measurements}

Subjects' height was measured without shoes to the nearest centimeter. Weight was measured to the nearest $0.1 \mathrm{~kg}$ with minimal clothing. BMI was calculated as weight divided by height squared $(\mathrm{kg} /$ $\mathrm{m}^{2}$ ). WC was measured the midway distance between the lower rib and anterior superior iliac crest by one of 2 different nurses for each subject. BP was measured on the right upper arm with an automated device (TM-2655P; PMS Instruments, Higashi-Ikebukuro, Toshima-Ku, Tokyo, Japan) after subjects rested for at least 15 minutes. Venous blood was drawn after a 12-hour overnight fast and 24-hour abstinence from vigorous activity. Standard enzymatic measurements of total cholesterol (TC), high-density lipoprotein cholesterol (HDLC), low-density lipoprotein cholesterol (LDL-C), triglyceride (TG), and fasting blood glucose (FBG) were made using fresh serum samples.

\section{Definition of Obesity and Metabolic Syndrome}

We followed NCEP-ATP III Asian guidelines to define metabolic syndrome, wherein subjects with more than 3 of the following abnormal values are defined as having metabolic syndrome: ${ }^{7}$

- central obesity (WC $\geq 90 \mathrm{~cm}$ for men, $\geq 80 \mathrm{~cm}$ for women)

- $\mathrm{BP} \geq 130 / 80 \mathrm{~mm} \mathrm{Hg}$,

- $\mathrm{TG} \geq 150 \mathrm{mg} / \mathrm{dL}$,

- $\mathrm{FBG} \geq 110 \mathrm{mg} / \mathrm{dL}$,

- and LDL-C $<40 \mathrm{mg} / \mathrm{dL}$ (for men) or $<50$ $\mathrm{mg} / \mathrm{dL}$ (for women).

\section{Statistical Analysis}

We used the ANOVA test with post hoc analysis to evaluate the mean values for metabolic parameters in the 4 groups of subjects. Using a general linear model, we analyzed the results adjusted for age and amount of smoking. We calculated the odds ratio of elevated FBG and TG in each group using multiple logistic regression adjusted for age and amount of smoking. We used the $\chi^{2}$ test to evaluate the prevalence of abnormal metabolic parameters and metabolic syndrome. Significance level was defined as $P<.05$ as determined by SPSS version 11.0.

\section{Results}

\section{Demographic Analysis: NG, COG, GOG, and COM}

In men, $1.5 \%$ of subjects were underweight (BMI $\left.<18.5 \mathrm{~kg} / \mathrm{m}^{2}\right), 35.6 \%$ were normal $(18.5 \leq \mathrm{BMI}<$ $\left.22.9 \mathrm{~kg} / \mathrm{m}^{2}\right), 28.7 \%$ were overweight $(23.0 \leq$ BMI $<24.9 \mathrm{~kg} / \mathrm{m}^{2}$ ), and $34.4 \%$ were obese (BMI $\left.\geq 25.0 \mathrm{~kg} / \mathrm{m}^{2}\right)$. In women, $3 \%$ of subjects were underweight (BMI $\left.<18.5 \mathrm{~kg} / \mathrm{m}^{2}\right), 50.1 \%$ were normal $\left(18.5 \leq \mathrm{BMI}<22.9 \mathrm{~kg} / \mathrm{m}^{2}\right), 21.9 \%$ were overweight $\left(23.0 \leq \mathrm{BMI}<24.9 \mathrm{~kg} / \mathrm{m}^{2}\right)$, and $25.0 \%$ were obese $\left(\mathrm{BMI} \geq 25.0 \mathrm{~kg} / \mathrm{m}^{2}\right)$.

The number of subjects in each group were:

- NG, 43,710 (62.9\%);

- COG, 3925 (5.6\%);

- GOG, 7597 (10.9\%);

- and COM, 14,303 (20.6\%).

All demographic parameters in the 3 obese groups showed significantly different values in comparison to the NG. The men in the COG were, on average, older and showed higher amounts of smoking than those in the other obese groups. All female subjects smoked much less than the men, and women in the COM group were, on average, 4 years older than 
Table 1. Demographic Analysis: NG, COG, GOG, and COM Groups of Korean Men and Women

\begin{tabular}{|c|c|c|c|c|c|c|}
\hline & & $\begin{array}{c}\text { NG } \\
(\mathrm{n}=43,710 \\
62.9 \%)\end{array}$ & $\begin{array}{c}\text { COG } \\
(\mathrm{n}=3925, \\
5.6 \%)\end{array}$ & $\begin{array}{c}\text { GOG } \\
(\mathrm{n}=7597, \\
10.9 \%)\end{array}$ & $\begin{array}{c}\mathrm{COM} \\
(\mathrm{n}=14,303 \\
20.6 \%)\end{array}$ & $P$ Value* \\
\hline \multirow[t]{2}{*}{ Age (years) } & Male & $44.1 \pm 9.9$ & $49.5 \pm 10.1$ & $43.6 \pm 8.7$ & $45.7 \pm 9.5$ & $<.001$ \\
\hline & Female & $41.8 \pm 10.0$ & $50.8 \pm 10.8$ & $45.3 \pm 9.6$ & $50.9 \pm 10.3$ & $<.001$ \\
\hline \multirow[t]{2}{*}{ Smoking (pack/year) } & Male & $14.0 \pm 13.9$ & $19.2 \pm 17.7$ & $13.3 \pm 13.4$ & $16.5 \pm 16.0$ & $<.001$ \\
\hline & Female & $0.4 \pm 2.4$ & $0.5 \pm 3.1$ & $0.1 \pm 1.5$ & $0.4 \pm 2.7$ & $<.001$ \\
\hline \multirow[t]{2}{*}{ Weight (kg) } & Male & $63.7 \pm 6.6$ & $71.7 \pm 5.0$ & $73.4 \pm 5.1$ & $80.2 \pm 7.4$ & $<.001$ \\
\hline & Female & $52.9 \pm 5.3$ & $58.2 \pm 4.7$ & $62.2 \pm 4.4$ & $66.9 \pm 6.8$ & $<.001$ \\
\hline \multirow[t]{2}{*}{ Waist $(\mathrm{cm})$} & Male & $79.8 \pm 5.6$ & $91.6 \pm 1.9$ & $86.0 \pm 2.6$ & $94.5 \pm 4.2$ & $<.001$ \\
\hline & Female & $70.3 \pm 5.0$ & $82.8 \pm 3.0$ & $76.3 \pm 2.4$ & $86.8 \pm 5.7$ & $<.001$ \\
\hline \multirow[t]{2}{*}{ BMI $\left(\mathrm{kg} / \mathrm{m}^{2}\right)$} & Male & $22.1 \pm 1.8$ & $24.0 \pm 0.7$ & $25.9 \pm 0.9$ & $27.5 \pm 1.8$ & $<.001$ \\
\hline & Female & $21.3 \pm 1.9$ & $23.5 \pm 1.1$ & $25.9 \pm 0.9$ & $29.6 \pm 2.2$ & $<.001$ \\
\hline
\end{tabular}

All values are mean \pm SD by ANOVA test with post hoc analysis. NG, normal group (normal BMI with normal WC); COG, centrally obese group (normal BMI with high WC); GOG, generally obese group (high BMI with normal WC); COM, combined obese group (high BMI and high WC); BMI, body mass index.

${ }^{*} P$ value by general linear model with age and smoking amount adjustment among groups.

men in that same group. After adjusting for age and amount of smoking, the obese groups' parameters were still significantly different from the NG. Body weight, WC, and BMI were highest in the COM. Body weight and BMI in the GOG were higher than in the COG (Table 1).

\section{Comparison of Metabolic Parameters \\ Men}

Almost all metabolic parameters for men (except HDL-C) in the COM were higher than in the other 3 groups. In addition, all metabolic parameters were lower in the NG, except for levels of HDL-C. TC, HDL-C, LDL-C, and BP were similar in the COG and the GOG. Yet TG and FBG were higher in the COG than in the GOG (Table 2).

\section{Women}

All metabolic parameters for women showed significantly different values for the normal compared with the 3 obese groups. As was true for the men, women's results were significantly different after adjusting for age and amount of smoking. Almost all metabolic parameters in the female COM group

Table 2. Comparison of Metabolic Parameters for NG, COG, GOG, and COM Korean Men

\begin{tabular}{lccccc}
\hline & $\begin{array}{c}\text { NG } \\
(\mathrm{n}=24,215, \\
60.5 \%)\end{array}$ & $\begin{array}{c}\text { COG } \\
(\mathrm{n}=1538, \\
3.9 \%)\end{array}$ & $\begin{array}{c}\text { GOG } \\
(\mathrm{n}=5730, \\
14.3 \%)\end{array}$ & $\begin{array}{c}\text { COM } \\
(\mathrm{n}=8527, \\
21.3 \%)\end{array}$ & $P$ Value* \\
\hline TC (mg/dL) & $188.4 \pm 33.5$ & $200.4 \pm 34.0$ & $198.3 \pm 33.9$ & $201.7 \pm 33.9 \dagger$ & $<.001$ \\
HDL-C (mg/dL) & $50.3 \pm 11.8$ & $47.0 \pm 10.9 \ddagger$ & $46.4 \pm 9.7 \dagger$ & $45.0 \pm 9.4$ & $<.001$ \\
TG (mg/dL) & $131.3 \pm 76.6$ & $172.8 \pm 91.9 \$$ & $165.7 \pm 89.7$ & $189.2 \pm 101.1 \dagger \neq$ & $<.001$ \\
Glucose (mg/dL) & $99.4 \pm 22.6$ & $106.4 \pm 26.6 \$$ & $102.6 \pm 20.8$ & $106.2 \pm 23.3 \dagger$ & $<.001$ \\
LDL-C (mg/dL) & $111.7 \pm 30.6$ & $118.8 \pm 32.7$ & $118.7 \pm 31.0$ & $118.8 \pm 32.4$ & $<.001$ \\
s-BP (mm Hg) & $118.8 \pm 15.5$ & $124.7 \pm 16.2$ & $125.1 \pm 15.6$ & $129.1 \pm 15.7 \dagger \neq$ & $<.001$ \\
d-BP $(\mathrm{mm} \mathrm{Hg})$ & $74.0 \pm 10.9$ & $78.0 \pm 10.7$ & $78.0 \pm 11.3$ & $80.9 \pm 11.3 \dagger \neq$ & $<.001$ \\
\hline
\end{tabular}

All values are mean \pm SD. NG, normal group (normal BMI with normal WC); COG, centrally obese group (normal BMI with high WC); GOG, generally obese group (high BMI with normal WC); COM, combined obese group (high BMI and WC); TC, total cholesterol; HDL-C, high-density lipoprotein cholesterol; TG, triglyceride; LDL-C, low-density lipoprotein cholesterol; s-BP, systolic blood pressure; d-BP, diastolic blood pressure.

$\dagger, \ddagger$, and $\S$ are marked in groups with higher values and $P<.05$ by ANOVA test.

* $P$ value by general linear model with age and smoking amount adjustment among groups.

† Comparison between GOG and COM.

$\ddagger$ Comparison between COG and COM.

$\$$ Comparison between COG and GOG. 
Table 3. Comparison of Metabolic Parameters for NG, COG, GOG, and COM Korean Women

\begin{tabular}{|c|c|c|c|c|c|}
\hline & $\begin{array}{c}\text { NG } \\
(\mathrm{n}=19,495 \\
66.0 \%)\end{array}$ & $\begin{array}{c}\text { COG } \\
(\mathrm{n}=2387, \\
8.1 \%)\end{array}$ & $\begin{array}{c}\text { GOG } \\
(\mathrm{n}=1867 \\
6.3 \%)\end{array}$ & $\begin{array}{c}\text { COM } \\
(\mathrm{n}=5776 \\
19.6 \%)\end{array}$ & $P$ Value \\
\hline $\mathrm{TC}(\mathrm{mg} / \mathrm{dL})$ & $182.5 \pm 34.0$ & $198.8 \pm 37.7 \dagger$ & $95.2 \pm 35.0$ & $203.1 \pm 37.0 \neq \$$ & $<.001$ \\
\hline HDL-C (mg/dL) & $57.5 \pm 12.8$ & $53.8 \pm 12.8 \$$ & $53.6 \pm 11.8 \neq$ & $51.3 \pm 11.5$ & $<.001$ \\
\hline $\mathrm{TG}(\mathrm{mg} / \mathrm{dL})$ & $94.0 \pm 53.9$ & $129.5 \pm 77.8 \dagger$ & $119.0 \pm 70.0$ & $145.5 \pm 82.7 \ddagger \S$ & $<.001$ \\
\hline Glucose (mg/dL) & $93.4 \pm 14.3$ & $101.1 \pm 26.1 \dagger$ & $97.2 \pm 17.1$ & $104.4 \pm 26.3 \neq \S$ & $<.001$ \\
\hline LDL-C (mg/dL) & $106.1 \pm 29.7$ & $119.0 \pm 33.7$ & $117.7 \pm 31.6$ & $122.6 \pm 33.6 \neq \$$ & $<.001$ \\
\hline s-BP (mm Hg) & $110.7 \pm 16.4$ & $121.1 \pm 19.4$ & $120.5 \pm 18.3$ & $129.1 \pm 19.2 \neq \S$ & $<.001$ \\
\hline d-BP (mm Hg) & $70.2 \pm 10.1$ & $74.6 \pm 11.1$ & $74.6 \pm 11.2$ & $79.0 \pm 11.4 \neq \S$ & $<.001$ \\
\hline
\end{tabular}

All values are mean \pm SD. NG, normal group (normal BMI with normal WC); COG, centrally obese group (normal BMI with high WC); GOG, generally obese group (high BMI with normal WC); COM, combined obese group (high BMI and WC); TC, total cholesterol; HDL, high-density lipoprotein cholesterol; TG, triglyceride; LDL, low-density lipoprotein cholesterol; s-BP, systolic blood pressure; d-BP, diastolic blood pressure.

$\dagger, \neq$, and $₫$ are marked in groups with higher values and $P<.05$ by ANOVA test.

* $P$ value by general linear model with age and smoking amount adjustment among groups.

† Comparison between COG and GOG.

$\ddagger$ Comparison between GOG and COM.

$\$$ Comparison between COG and COM.

measured higher (except for HDL-C), as was seen with the male subjects. All metabolic parameters were lower in the NG, except HDL-C, but TC was higher in the COG than in the GOG, and this was different from the men's results. As was seen in the male subjects, TG and FBG were higher in the COG than in the GOG. HDL-C, LDL-C, and BP in the COG and the GOG showed no differences (Table 3).

\section{Odds Ratios for Elevated TG and FBG and Means for Abnormal Metabolic Parameters}

The COM group showed the highest elevations of FBG and TG compared with the other groups. The COG had more abnormal FBG and TG levels than the GOG. The odds ratios of having elevated
FBG $(\geq 110 \mathrm{mg} / \mathrm{dL})$ in the 3 obese groups compared with the NG in men were: COG, $1.82(P<$ .001); GOG, $1.74(P<.001)$; and COM, $2.35(P<$ $.001)$. In women, the odds ratios of having elevated FBG were: COG, $1.91(P<.001)$; GOG, $1.77(P<$ $.001)$; and COM, $3.20(P<.001)$. The odds ratios for male subjects were $2.38(P<.001)$ in the COG, $2.20(P<.001)$ in the GOG, and $3.26(P<.001)$ in the COM group for elevated TG ( $\geq 150 \mathrm{mg} / \mathrm{dL})$. In females, the odds ratios of having elevated TG were $2.01(P<.001)$ in the COG, $1.96(P<.001)$ in the GOG, and $3.05(P<.001)$ in the COM (Table 4).

Although the odds ratios of having elevated FBG and TG were higher in the 3 obese groups than in the NG, we did not find significant differ-

Table 4. Odds Ratios for High FBG and TG in NG, COG, GOG, and COM Groups

\begin{tabular}{|c|c|c|c|c|c|c|}
\hline & \multicolumn{3}{|c|}{ Men } & \multicolumn{3}{|c|}{ Women } \\
\hline & $\begin{array}{c}\mathrm{FBG} \geq 110 \mathrm{mg} / \mathrm{dL}, \\
\mathrm{OR}(95 \% \mathrm{CI})\end{array}$ & $\begin{array}{c}\mathrm{TG} \geq 150 \mathrm{mg} / \mathrm{dL}, \\
\text { OR }(95 \% \mathrm{CI})\end{array}$ & $P$ Value* & $\begin{array}{c}\text { FBG } \geq 110 \mathrm{mg} / \mathrm{dL}, \\
\text { OR }(95 \% \mathrm{CI})\end{array}$ & $\begin{array}{c}\mathrm{TG} \geq 150 \mathrm{mg} / \mathrm{dL}, \\
\text { OR }(95 \% \mathrm{CI})\end{array}$ & $P$ Value ${ }^{*}$ \\
\hline NG & 1 & 1 & & 1 & 1 & \\
\hline $\mathrm{COG}$ & $1.82(1.59-2.09)$ & $2.38(2.13-2.67)$ & $<.001$ & $1.91(1.65-2.21)$ & $2.01(1.80-2.25)$ & $<.001$ \\
\hline GOG & $1.74(1.60-1.89)$ & $2.20(2.06-2.34)$ & $<.001$ & $1.77(1.48-2.11)$ & $1.96(1.73-2.22)$ & $<.001$ \\
\hline $\mathrm{COM}$ & $2.35(2.20-2.52)$ & $3.26(3.08-3.44)$ & $<.001$ & $3.20(2.89-3.54)$ & $3.05(2.82-3.30)$ & $<.001$ \\
\hline
\end{tabular}

FBG, fasting blood sugar; TG, triglyceride; NG, normal group (normal BMI with normal WC); COG, centrally obese group (normal BMI with high WC); GOG, generally obese group (high BMI with normal WC); COM, combined obese group (high BMI and WC); $\mathrm{OR}$, odds ratio; CI, confidence interval.

${ }^{*} P<.001$, statistically significant difference compared to the NG after age and smoking amount adjustment by the multiple logistic regression model. 


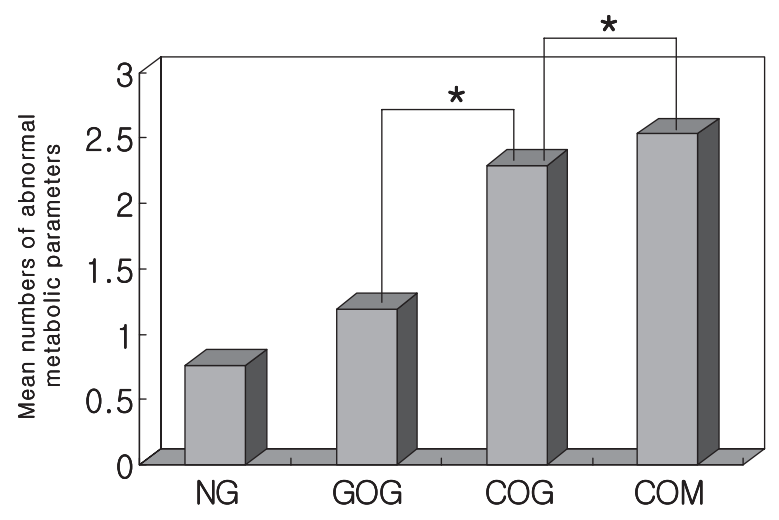

Figure 1. Mean values for abnormal metabolic parameters for men in the normal group (NG), generally obese group (GOG), centrally obese group (COG), and combined obese group (COM): 3rd National Cholesterol Education Program-Adults Treatment Panel III (NCEPATP III) Asian guideline. $*, P>~ .05$, statistically significant difference between groups.

ences between the COG and the GOG using multiple logistic regression analysis. However, the COM had higher mean numbers for the abnormal metabolic parameters (according to the NECPATP III Asian guideline) than the other 3 groups. In addition, higher mean numbers for abnormal metabolic parameters were found in the COG compared with the GOG, for both men and women (Figures 1 and 2).

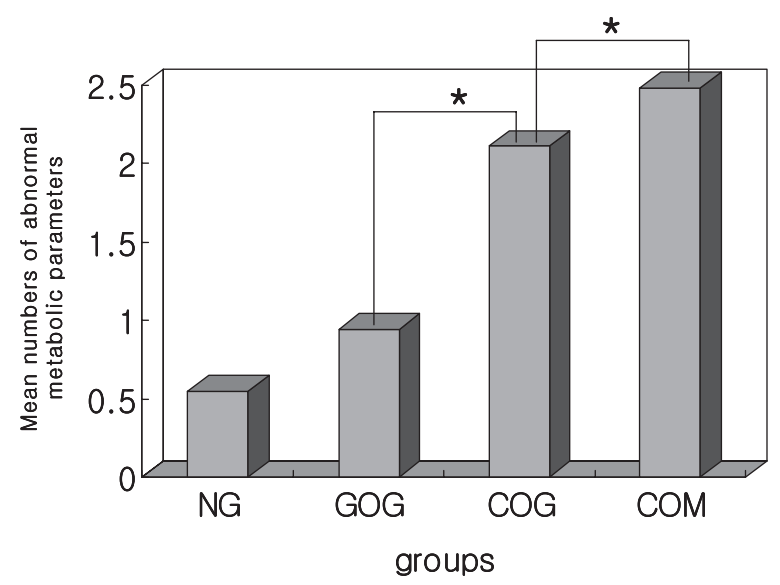

Figure 2. Mean values for abnormal metabolic parameters for women in the normal group (NG), generally obese group (GOG), centrally obese group (COG), and combined obese group (COM): 3rd National Cholesterol Education Program-Adults Treatment Panel III (NCEP-ATP III) Asian guideline. $*, P>.05$, statistically significant difference between groups.
Prevalence of Abnormal Metabolic Parameters and Metabolic Syndrome

Tables 5 and 6 show the prevalence of abnormality for each metabolic parameter and for metabolic syndrome in men and women. In 4 of the metabolic syndrome components (except WC), there were small differences among the 3 obese groups. However, we found a higher prevalence of metabolic syndrome in the COG $39.1 \%$ in men, $33.0 \%$ in women) than in the GOG (9.7\% in men, $7.8 \%$ in women), although there were no differences in the odds ratios of having abnormalities of metabolic parameters.

\section{Discussion}

The results of this study indicate the role of WC in metabolic parameters and show that the prevalence of metabolic syndrome in the group with high WC and normal BMI (the COG) was higher than in the group with high BMI and normal WC (the GOG), as defined by NCEP-ATP III Asian guideline. ${ }^{7}$ In addition, the mean values for abnormal metabolic parameters in the COG were higher than for the GOG. According to our results, Korean subjects with a high $\mathrm{WC}$ are at greater risk for developing metabolic syndrome.

Obesity is associated with higher TC, LDL-C, and TG levels as well as lower HDL-C plasma concentrations. ${ }^{8,9}$ Furthermore, elevated levels of serum TGs are commonly associated with insulin resistance and other cardiovascular risk factors. ${ }^{10}$ The results of many epidemiologic studies support the hypothesis that visceral obesity is the main risk factor in the clinical development of diabetes in genetically susceptible subjects. ${ }^{1-14}$

Similar to previous studies, we found TG and FBG in men to be higher in the COG than the GOG. In addition to TG, FBG abnormalities and TC levels in women were also higher in the COG than in the GOG. We also found that the odds ratios of having elevated TG and FBG in the 3 obese groups were higher than the NG. However, there were no significant differences of odds ratios that having elevated TG and FBG between the COG and the GOG. These findings suggest that WC plays a crucial role in the development of metabolic abnormalities and metabolic syndrome in centrally obese Koreans. These subjects are at higher risk of developing metabolic syndrome than GOG subjects, who have a higher BMI but fewer instances of metabolic syndrome. 
Table 5. Prevalence of Abnormal Metabolic Parameters and Metabolic Syndrome for Men in the NG, COG, GOG, and coM Groups.

\begin{tabular}{|c|c|c|c|c|c|}
\hline & NG (\%) & COG (\%) & GOG (\%) & $\operatorname{COM}(\%)$ & $P$ Value \\
\hline Waist ( $\geq 90 \mathrm{~cm})$ & 0 & 100 & 0 & 100 & $<.001$ \\
\hline HDL-C (<40 mg/dL) & 16.7 & 23.9 & 24.7 & 29.5 & $<.001$ \\
\hline $\mathrm{TG}(\geq 150 \mathrm{mg} / \mathrm{dL})$ & 29.7 & 51.7 & 47.5 & 58.3 & $<.001$ \\
\hline $\mathrm{FBG}(\geq 110 \mathrm{mg} / \mathrm{dL})$ & 12.3 & 24.0 & 18.6 & 26.3 & $<.001$ \\
\hline $\mathrm{BP}(\geq 130 / 80 \mathrm{~mm} \mathrm{Hg})$ & 35.6 & 52.0 & 50.5 & 63.4 & $<.001$ \\
\hline MS (\%) & 4.2 & 39.1 & 9.7 & 49.7 & $<.001$ \\
\hline
\end{tabular}

NG, normal group (normal BMI with normal WC); COG, centrally obese group (normal BMI with high WC); GOG, generally obese group (high BMI with normal WC); COM, combined obese group (high BMI and WC); HDL-C, high-density lipoprotein cholesterol; TG, triglyceride; FBG, fasting blood glucose; BP, blood pressure; MS, metabolic syndrome defined in NCEP-ATP III (Asian guideline). $P$ values were from $\chi^{2}$ test.

We know that many obese people are at risk for high BP. We found that the 3 obese groups had higher $\mathrm{BP}$ readings than the NG. However, there was no difference in mean BP between the COG and the GOG, although for female subjects the odds ratio of elevated BP in the COG compared with the GOG was a little higher (data not shown), with $42.9 \%$ in the female COG vs $37.7 \%$ in the female GOG having elevated BP.

$\mathrm{WC}$ and $\mathrm{BMI}$ are significant predictors of obesity-related metabolic disorders. ${ }^{15}$ Misra et al found that Asian Indians have relatively higher truncal and abdominal fat mass compared with Caucasians and African Americans, despite similar or lower average WC. ${ }^{16}$ Misra et al proposed 2 WC action levels in Asian Indians: action level 1 (men $\geq 78 \mathrm{~cm}$, women $\geq 72 \mathrm{~cm})$ and action level $2(\mathrm{men} \geq 90 \mathrm{~cm}$, women $\geq 80 \mathrm{~cm})$. They suggested that subjects with a WC above action level 2 should seek advice from a physician for medically supervised weight management. ${ }^{17}$ This study showed the importance of
WC for those Asians with normal BMI and high WC (at the same level as Misra's active level 2).

Other recent studies have proposed and confirmed the presence of uncomplicated obesity. ${ }^{18,19}$ Hoefle et al reported that both total and central obesity are associated with insulin resistance and atherogenic lipoprotein profiles. However, only central obesity is significantly and independently predictive of the 2-year vascular mortality in coronary patients. ${ }^{20}$ Furthermore, it has been suggested that WC is a better measurement of central obesity than waist-hip ratio, ${ }^{21}$ and it has been posited that WC is more closely correlated with an atherogenic lipid profile than waist-hip ratio. ${ }^{22}$ Similarly, our study finds the mean values of TG and FBG and the mean values for abnormal metabolic parameters in the COG to be higher than in the GOG.

The role of BMI in predicting an unfavorable metabolic profile has been recently discussed and criticized. ${ }^{23,24}$ Gianluca et al reported a significant increase in $\mathrm{BP}$ and insulin resistance parameters

Table 6. Prevalence of Abnormal Metabolic Parameters and Metabolic Syndrome for Women in the NG, COG, GOG, and COM Groups

\begin{tabular}{lcccrr}
\hline & NG $(\%)$ & COG $(\%)$ & GOG $(\%)$ & COM (\%) & $P$ Value \\
\hline Waist $(\geq 80 \mathrm{~cm})$ & 0 & 100 & 0 & 100 & $<.001$ \\
HDL-C $(<50 \mathrm{mg} / \mathrm{dL})$ & 2.8 & 39.9 & 39.5 & 48.5 & $<.001$ \\
TG $(\geq 150 \mathrm{mg} / \mathrm{dL})$ & 11.5 & 28.4 & 23.1 & 37.2 & $<.001$ \\
Glucose $(\geq 110 \mathrm{mg} / \mathrm{dL})$ & 4.9 & 14.3 & 9.7 & 21.3 & $<.001$ \\
BP $(\geq 130 / 80 \mathrm{~mm} \mathrm{Hg})$ & 21.4 & 33.0 & 7.9 & 57.9 & $<.001$ \\
MS $(\%)$ & 2.6 & & 7.8 & 46.5 & $<.001$ \\
\hline
\end{tabular}

NG, normal group (normal BMI with normal WC); COG, centrally obese group (normal BMI with high WC); GOG, generally obese group (high BMI with normal WC); COM, combined obese group (high BMI and WC); HDL-C, high-density lipoprotein cholesterol; TG, triglyceride; BP, blood pressure; MS, metabolic syndrome defined in NCEP-ATP III (Asian guideline). $P$ values were from $\chi^{2}$ test. 
only in obese subjects with BMI $>40 \mathrm{~kg} / \mathrm{m}^{2}$ in the Italian obese population. ${ }^{25}$ They also reported that $\mathrm{BMI}$ and insulin resistance are related only in conditions of high-degree obesity and that insulin resistance can contribute independently to an increased cardiovascular risk, as previously reported. ${ }^{26-28}$

As many Asians may have central obesity with $\mathrm{BMI}<25 \mathrm{~kg} / \mathrm{m}^{2}$, we should focus on educating this population about the risk of being centrally obese. Our results support the proposal to adopt measurement of WC as a valuable tool. WC can help to assess health risks for obese and overweight patients in both public health and primary care clinics. ${ }^{29,30}$ In our study, $5.6 \%$ of subjects were in the COG, so we should not neglect this population. We suggest measuring WC for those with central obesity, even if they are not generally obese, to assess the risk of metabolic syndrome.

This study has some limitations. The study was cross-sectional, preventing assertion of a causal relationship between WC and metabolic syndrome. The data were sampled from only one hospital, so there was a possibility of selection bias; however, the prevalence of obesity in this study was $31.5 \%$ (35.6\% in men, $25.9 \%$ in women), correlating with the third national health and nutrition survey in 2001. ${ }^{1}$ We adjusted only for age and amount of smoking without adjusting for daily activity, amount of exercise, or socioeconomic status. However, the large sample size strengthens the results of this study and may provide evidence for the prevalence of metabolic syndrome in Koreans. The study also is consistent with other national studies by emphasizing how WC is related to metabolic syndrome. ${ }^{31,32}$

In conclusion, among Koreans, subjects in the COG have a higher incidence of metabolic abnormalities and metabolic syndrome than those who are not obese or are generally obese.

We thank Ju Hee Song, Yun Jung Lee, and Jung Ja Woo for their excellent assistance and help with data collection. We also thank Adam Thorsteinson for his review of the manuscript's translation into English.

\section{References}

1. Report on national health and nutrition survey 2001. Seoul (Korea): Korean Ministry of Health and Welfare; 2002.

2. Lakka HM, Laaksonen DE, Lakka TA, et al. The metabolic syndrome and total and cardiovascular disease mortality in middle-aged men. JAMA 2002;288: 2709-16.

3. Ford ES. The metabolic syndrome and mortality from cardiovascular disease and all-causes: findings from the National Health and Nutrition Examination Survey II Mortality Study. Atherosclerosis 2004; 173:309-14.

4. Hu G, Qiao Q, Tuomilehto J, Balkau B, BorchJohnsen K, Pyorala K; DECODE Study Group. Prevalence of the metabolic syndrome and its relation to all-cause and cardiovascular mortality in nondiabetic European men and women. Arch Intern Med 2004;164:1066-76.

5. Solymoss BC, Bourassa MG, Campeau L, et al. Effect of increasing metabolic syndrome score on atherosclerotic risk profile and coronary artery disease angiographic severity. Am J Cardiol 2004;93:159_ 64.

6. Okosun IS, Liao Y, Rotimi CN, Prewitt TE, Cooper RS. Abdominal adiposity and clustering of multiple metabolic syndrome in White, Black and Hispanic Americans. Ann Epidemiol 2000;10:263-70.

7. The Asia-Pacific perspective: redefining obesity and its treatment. Melbourne: International Diabetes Institute; 2000 Feb. Sponsored by the Regional Office for the Western Pacific (WPRO), World Health Organization, the International Association for the Study of Obesity, and the International Obesity Task Force.

8. Obesity: preventing and managing the global epidemic. Report of a WHO consultation on obesity. World Health Organ Tech Rep Ser 2000;894:1-253.

9. Clinical guidelines on the identification, evaluation and treatment of overweight and obesity in adults. The evidence report. Bethesda (MD): National Heart, Lung, and Blood Institute, National Institutes of Health; 1998 Sept. NIH Publication No. 98-4083.

10. Grundy SM. Hypertriglyceridemia, insulin resistance, and the metabolic syndrome. Am J Cardiol 1999;83:25F-29F

11. Lee $Y$, Hirose H, Ohneda M, Johnson McGarry J, and Unger R. $\beta$-cell lipotoxicity in the pathogenesis on non-insulin dependent diabetes mellitus of obese rats: impairment in adipocyte $\beta$-cell relationships. Proc Natl Acad Sci 1994;91:10878-82.

12. Maedler K, Spinas GA, Lehmann R, et al. Glucose induces beta-cell apoptosis via upregulation of the Fas receptor in human islet. Diabetes 2001;50:168390.

13. Unger RH, Orci L. Lipoapotosis: its mechanism and its disease. Biochim Biophys Acta 2002;1585:202-12.

14. Bosello O, Zamboni M. Visceral obesity and metabolic syndrome. Obesity reviews. 2000;1:47-56.

15. Baumgartner RN, Heymsfield SB, Roche AF. Human body composition and the epidemiology of chronic disease. Obes Res 1995;3:73-95.

16. Misra A, Vikram NK. Insulin resistance syndrome 
(metabolic syndrome) and obesity in Asian Indians: evidence and implications. Nutrition 2004;20:48291.

17. Misra A, Vikram NK, Gupta R, Pandey RM, Wasir JS, Gupta VP. Waist circumference cutoff points and action levels for Asian Indians for identification of abdominal obesity. Int J Obes Relat Metab Disord 2006;30:106-11.

18. Brochu M, Tchernof A, Dionne IJ, et al. What are the physical characteristics associated with a normal metabolic profile despite a high level of obesity in postmenopausal women? J Clin Endocrinol Metab 2001;86:1020-5.

19. Marchesini G, Melchionda N, Apolone G, et al. The metabolic syndrome in treatment-seeking obese persons. Metabolism 2004;53:435-40.

20. Hoefle G, Saely CH, Aczel S, Benzer W, Marte T, Langer P, Drexel H. Impact of total and central obesity on vascular mortality in patients undergoing coronary angiography. Int J Obes Relat Metab Disdord 2005;29:785-91.

21. Pouliot MC, Despres JP, Lemieux S, et al. Waist circumference and abdominal sagittal diameter: best simple anthropometric indexes of abdominal visceral adipose tissue accumulation and related cardiovascular risk in men and women. Am J Cardiol 1994;73: 460-68.

22. Despres JP, Lemieux I, Prud'homme D. Treatment of obesity: need to focus on high risk abdominally obese patients. BMJ 2001;322:716-20.

23. Janssen I, Katzmarzyk PT, Ross R. WC and not body mass index explains obesity-related health risk. Am J Clin Nutr 2004;79:379-84.

24. Rexrode M, Buring JE, Manson JE. Abdominal and total adiposity and risk of coronary heart dis- ease in men. Int J Obes Relat Metab Disord 2001; 25:1047-56.

25. Iacobellis G, Ribaudo MC, Zappaterreno A, Iannucci CV, Leonetti F. Prevalence of uncomplicated obesity in an Italian obese population. Obes Res 2005; 13:1116-20.

26. Reaven GM. Role of insulin resistance in human disease. Diabetes 1988;37:1595-607.

27. DeFronzo RA, Ferrannini E. Insulin resistance: a multifaceted syndrome responsible for NIDDM, obesity, hypertension, dyslipidemia, and atherosclerotic cardiovascular disease. Diabetes Care 1991;14: 173-94.

28. Iacobellis G, Ribaudo MC, Zappaterreno A, et al. Relationship of insulin sensitivity and left ventricular mass in uncomplicated obesity. Obes Res 2003;11: $518-24$

29. Clinical guidelines on the identification, evaluation, and treatment of overweight and obesity in adults: the evidence report. Obes Res 1998;6 Suppl 2:51S209S.

30. Seidell JC, Kahn HS, Williamson DF, Lissner L, Valdez R. Report from a Centers for Disease Control and Prevention Workshop on use of adult anthropometry for public health and primary health care. Am J Clin Nutr 2001;73:123-26.

31. Yeh WT, Chang HY, Yeh CJ, Tsai KS, Chen HJ, Pan WH. Do centrally obese Chinese with normal $\mathrm{BMI}$ have increase risk of metabolic disorders. Int J Obes Relat Metab Disord 2005;29:818-25.

32. Bigaard J, Frederiksen K, Tjonneland A, et al. Waist circumference and body composition in relation to all-cause mortality in middle-aged men and women. Int J Obes Relat Metab Disord 2005;29:778-84. 